\title{
THE HUMAN HAIR FOLLICLE AS SENTINEL FOR DRUGS EVALUATION: DEMONSTRATION OF TETRACYCLINE ADHESION TO HAIR FOLLICLE AS PROPOSED MECHANISM IN DYSFUNCTIONAL HAIR LOSS
}

\author{
Abrahám A. Embí BS MBA*1凶 (iD) \\ ${ }^{*} 113442$ SW 102 Lane, Miami Florida, USA 33186
}

DOI: https://doi.org/10.29121/granthaalayah.v8.i11.2020.2521

Article Type: Research Article

Article Citation: Abrahám A. Embí BS MBA. (2020). THE HUMAN HAIR FOLLICLE AS SENTINEL FOR DRUGS EVALUATION: DEMONSTRATION OF TETRACYCLINE ADHESION TO HAIR FOLLICLE AS PROPOSED MECHANISM IN DYSFUNCTIONAL HAIR LOSS. International Journal of Research -GRANTHAALAYAH, 8(11), 324-332.

https://doi.org/10.29121/granthaa layah.v8.i11.2020.2521

Received Date: 15 November 2020

Accepted Date: 30 November 2020

Keywords:

Tetracycline

Adhesion Keratin

Human Hair Follicle

Hair Follicle Apoptosis

Tetracycline Fluorescence

Dysfunctional Hair Loss

\section{ABSTRACT}

One mechanism of action of antibiotics such as tetracyclines involves the disruption of pathogens cell membranes. This author had previously demonstrated in vitro and in vivo the utility of a human miniorgan, a.k.a. hair follicle as sentinel in demonstrating the deleterious effect of alcohol by showing a disruption in metabolism.

In this manuscript, the hair follicle was again used in vitro as sentinel in direct contact with another exogenous substance in two forms, namely liquid and powder tetracycline. The results demonstrate the adhesion property of tetracycline as a mechanism causing deleterious effect on the biological active cells of the follicle's dermal papilla, and the consequent disruption in metabolism. Notably, it was documented a strong affinity of the antibiotic to the keratin skeleton of the hair follicle. In a recent published report, the adverse effect of tetracycline induction on experimentally deficient mitochondrial DNA (mtDNA) mouse was reversed and documented 30 days after discontinuation of the tetracycline diet. The experiments herein presented correlate and confirm previous findings of long term exposure to tetracycline causing not only damage the pathogen; but also healthy human cells. Since mtDNA may play a role in aging and ageassociated diseases: Beware of tetracycline therapy on the elderly.

\section{INTRODUCTION}

The hair follicle as sentinel was previously introduced in detecting changes in both in vitro and in vivo ethanol blood alcohol concentration [1]. The aim of this manuscript is to reintroduce the human hair follicle as sentinel, this time in vitro detecting effects from direct contact with a commonly used antibiotic, namely dry and liquid tetracycline (TET). A variety of in toto freshly plucked, human hairs were tested. The hair mainly consists of two parts, the follicle penetrating the skin and a visible part or shaft. The idea for these experiments resulted from experiments done in the early 1960's where the fluorescence property of TET was used in an attempt to identify gastric cancer cells, as we know ultraviolet light triggers fluorescence, thus the basis for that early research [2]. Recent reports of mitochondrial dysfunction in mitochondrial depleted mouse show "that hair loss and wrinkled skin after two months

(C) 2020 The Author(s). This is an open access article distributed under the terms of the Creative Commons Attribution License, which permits unrestricted use, distribution, and reproduction in any medium, provided the original author and source are credited. 
of doxycycline [which is a synthetic antibiotic derived from tetracycline (italics mine)] was reversed a month after doxycycline was stopped. Concluded was "that restoration of mitochondrial functions can reverse the skin and hair pathology...and alopecia was not due to loss of hair follicles or cessation of cycling; rather, the follicles were dysfunctional and could not produce normal hair shaft or completely lost this capability" [3]. Additional reports identified TET as a zinc chelator [4] and zinc transporters compounds, are prevalent in hair follicles [5]. Due to the body of evidence found in the aforementioned published reports, this author became intrigued as to the in vitro effect of liquid or dry TET on a human miniorgan a.k.a. the hair follicle [6]. Images and video recordings are introduced supporting the adhesive property of tetracycline on the human hair follicle as mechanism for the reported depletion of mitochondrial DNA.

\title{
2. MATERIALS AND METHODS
}

\subsection{MATERIALS}

UV light: Model UVG-4 Mini UV lamp with a wavelength of 254nm.

\author{
Medicine Dropper \\ Potassium FerrIcyanide Crystal. $\mathrm{K}_{3} \mathrm{Fe}(\mathrm{CN})_{6 .} . \mathrm{CSA} \#$ 13746-66- \\ Black and Gray Hairs Follicles plucked via tweezers from author's scalp, forearm and facial hair \\ Microscope glass slides: 25x75x1mm thickness. Pearl Cat. No. 7101 \\ Digital Video Microscope Celestron II model \# 44341, California, USA. \\ Images downloaded to an Apple Computer MacBook Pro Photo Application.
}

\subsection{METHODS}

Tetracycline capsules (500 mg) were pierced at one end and the golden yellow powder transferred to a white glass dinner plate. The power was divided by a double edge razor blade into 10 piles each estimated to contain 100 mg each. The subdivision progressed until to piles of 5 mgs each were reached (Figure 1).

Freshly plucked human hairs were placed on a glass slide and immersed in two drops of liquid tetracycline (TET). The liquid version was prepared diluting $5 \mathrm{mg}$ of TET powder in 2 drops of water (delivered by medicine dropper).

The Single Slide Preparation (SSP) is where a sample is placed on a glass slide and covered with a given dry or liquid material. Changes caused during the time dependent evaporation process are recorded.

The Sandwich (SDW) is when material is trapped between two equal glass slides. On the top slide samples are placed to record effects of any radiated energy penetrating the $1 \mathrm{~mm}$ thick glass.

Ultraviolet light was applied to SSP glass slides with the aim of identifying fluorescent TET adhesion to hair anatomical parts.

\section{RESULTS}

\section{Fluorescent Tetracycline Crystals Selective Adhesion to Follicles}

Three experiments consistently showed evaporated liquid TET, crystals detected by its fluorescent property selectively adhering to the hair follicles. In all samples, hair shafts also showed adhered TET crystals This evidence is unseen when the hair proper is in place. (Figures 1,1A). 


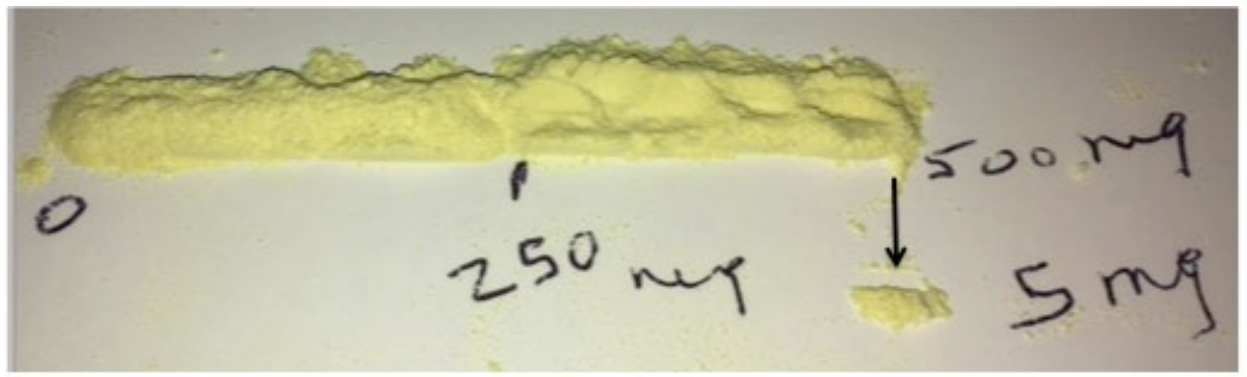

\section{Yellow Golden Powder from Pierced 500 mg Tetracycline Capsule Black Arrow: Estimated $5 \mathrm{mg}$ used for in vitro experiments}

Figure 1: Yellow golden tetracycline powder from $500 \mathrm{mg}$ capsule. Black Arrow: Pointing at estimated $5 \mathrm{mg}$ used for liquid tetracycline.

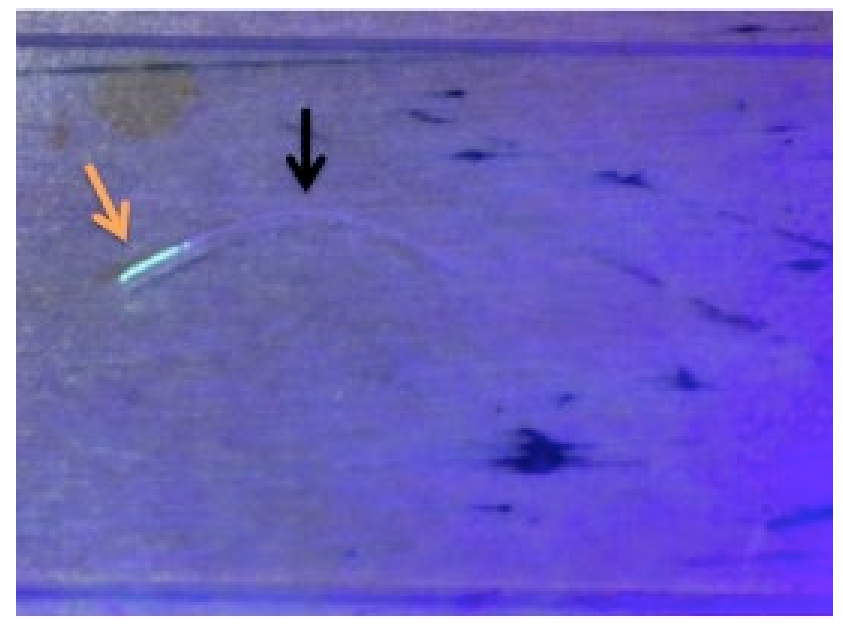

Figure 1A: Hair follicle under UV light exposure post SSP liquid tetracycline showing: Orange Arrow: Evaporated tetracycline powder adhesion to hair follicle. Black Arrow: Faint image of hair shaft.

Figure 2 below plus video link showing the physical removal of the hair highlighted by the orange arrow in Figure 1 above.

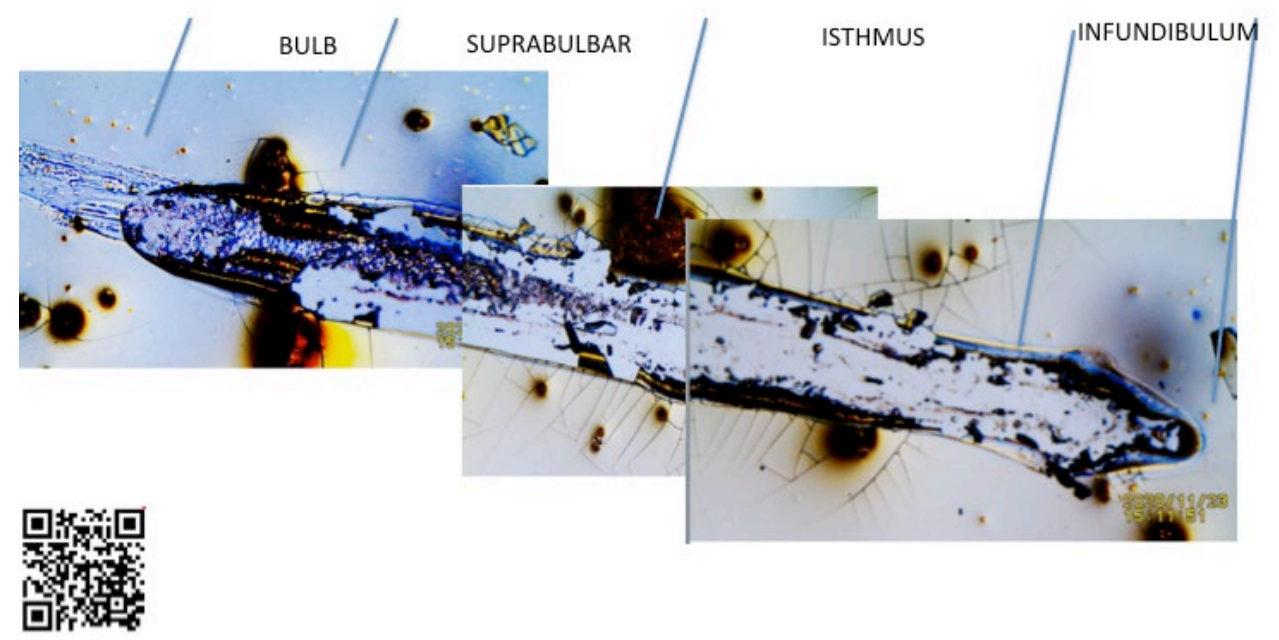

Figure 2: $n=3$ experiments done. Showing removed hair follicle material adhered to slide in SSP after liquid tetracycline dehydration. This preparation shows liquid tetracycline preferential adhesive properties towards the entire hair follicles. For additional details link to URL https://youtu.be/irYsD2KIiMQ Or Scan QR Code in left lower corner of image. 


\section{Human Hair Immersed in Saturated Liquid Tetracycline}

Adhesion to Keratin Skeleton

When a human hair on a glass slide is in contact with a saturated solution of liquid TET, only the keratin skeleton remains on the slide. This effect is governed by the degree of estimated TET \% saturation. The greater the amount of solute (TET mgs) in 3 medicine dropper water drops, the greater the soft tissue damage (Figures 3,4 )

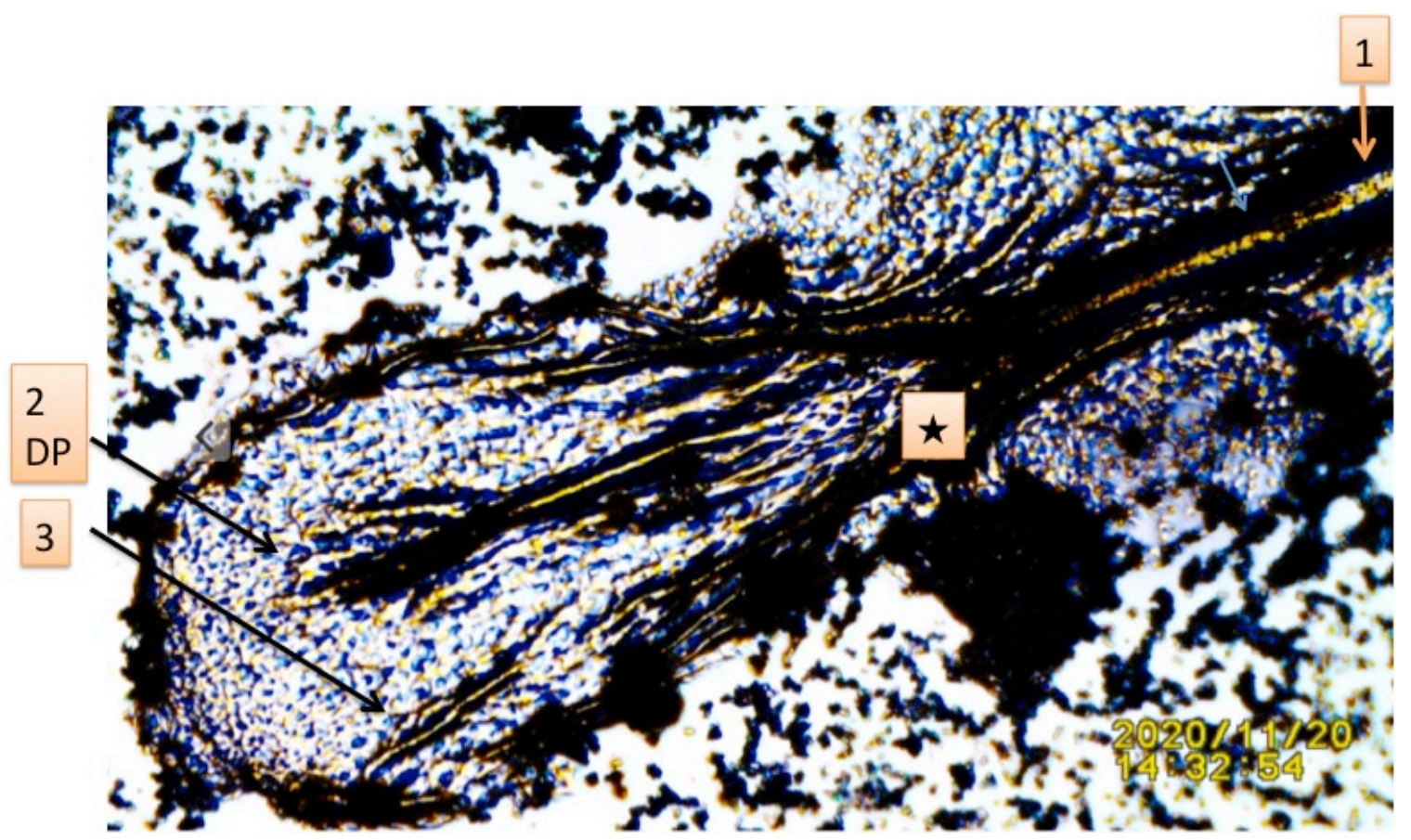

Figure 3: Liquid Tetracycline showing stained golden yellow hair follicle and shaft keratin skeleton. Notice the Dermal Papilla (DP) as primary starting point for hair follicle inner keratinized circulation channels. Orange arrow showing: 1= (right upper corner) Hair shaft cuticles, Black Arrow: (left side of image) 2= DP area.

$3=$ Secondary channel. $\star$ : Area amplified in figure 4 below.

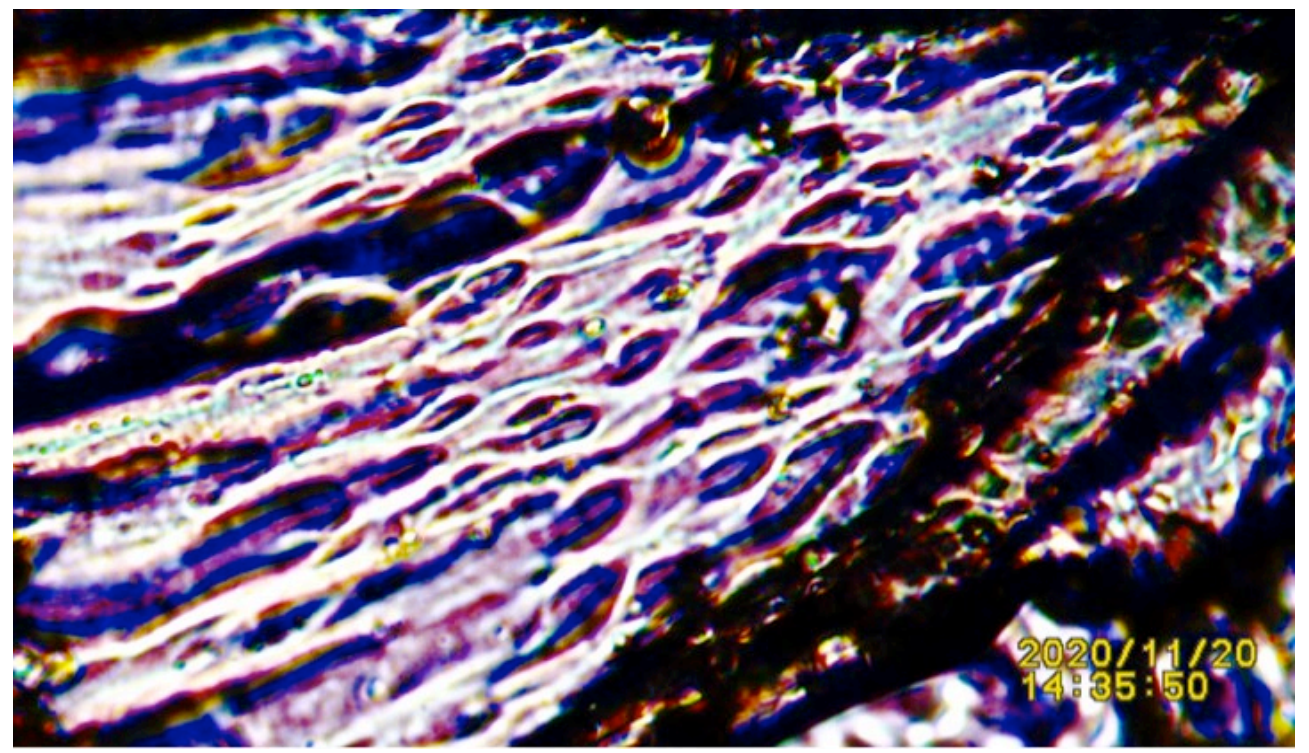

Figure 4: Amplified area as area highlighted by $\star$ in figure 3 above. Demonstrating complexity of hair follicle keratin skeleton. 


\section{Tetracycline Adhering To Keratin}

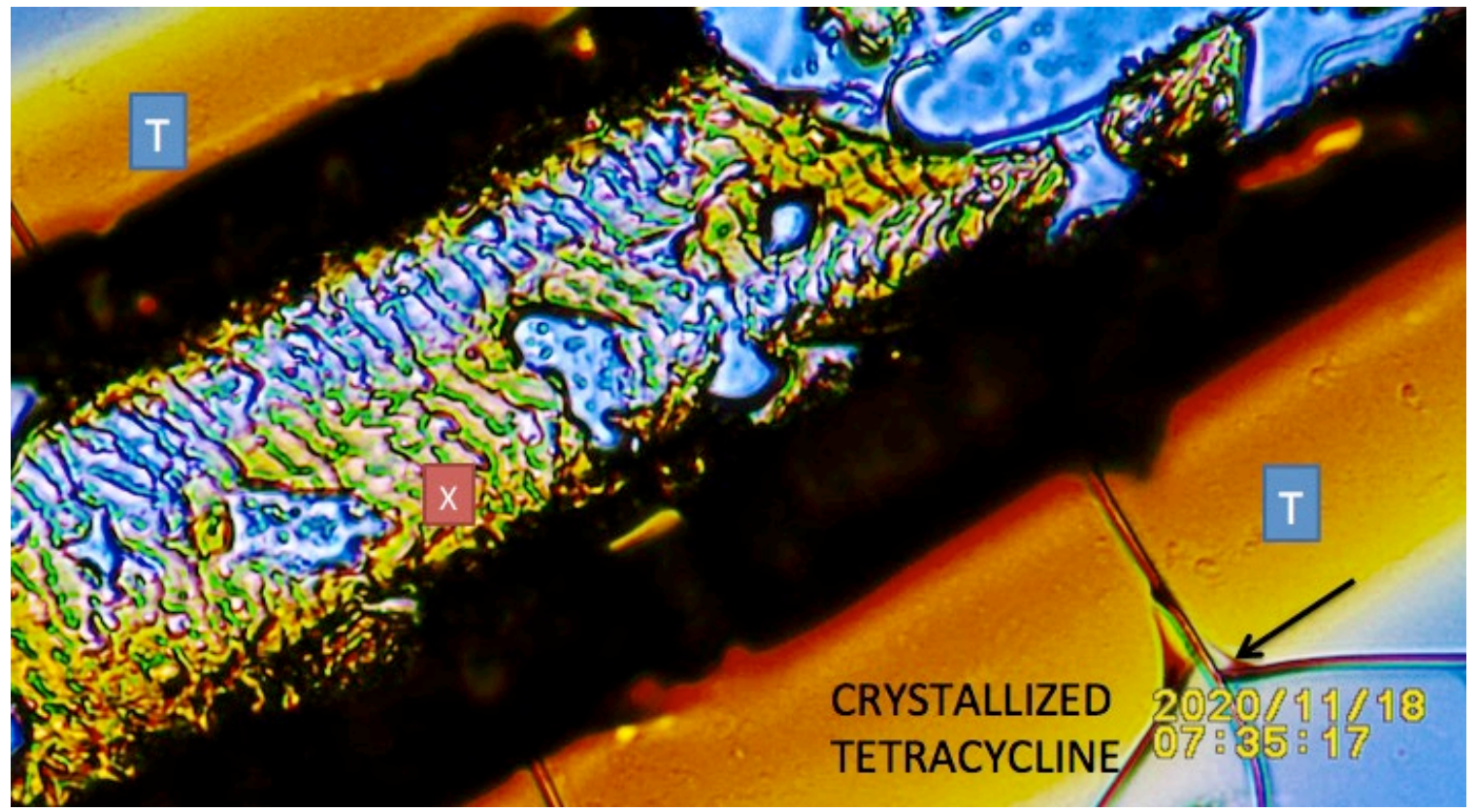

Figure 5: This time showing removed from slide human beard hair post SSP K3Fe. Shown is adhered tetracycline to detached keratin based hair cuticles, Black Arrow: Right side of slide, pointing at dry tetracycline break-lines. T= Evaporated liquid Tetracycline.

\section{Images Showing Tetracycline Affinity Towards Hair Follicle Active Metabolic Dermal Papilla Area}
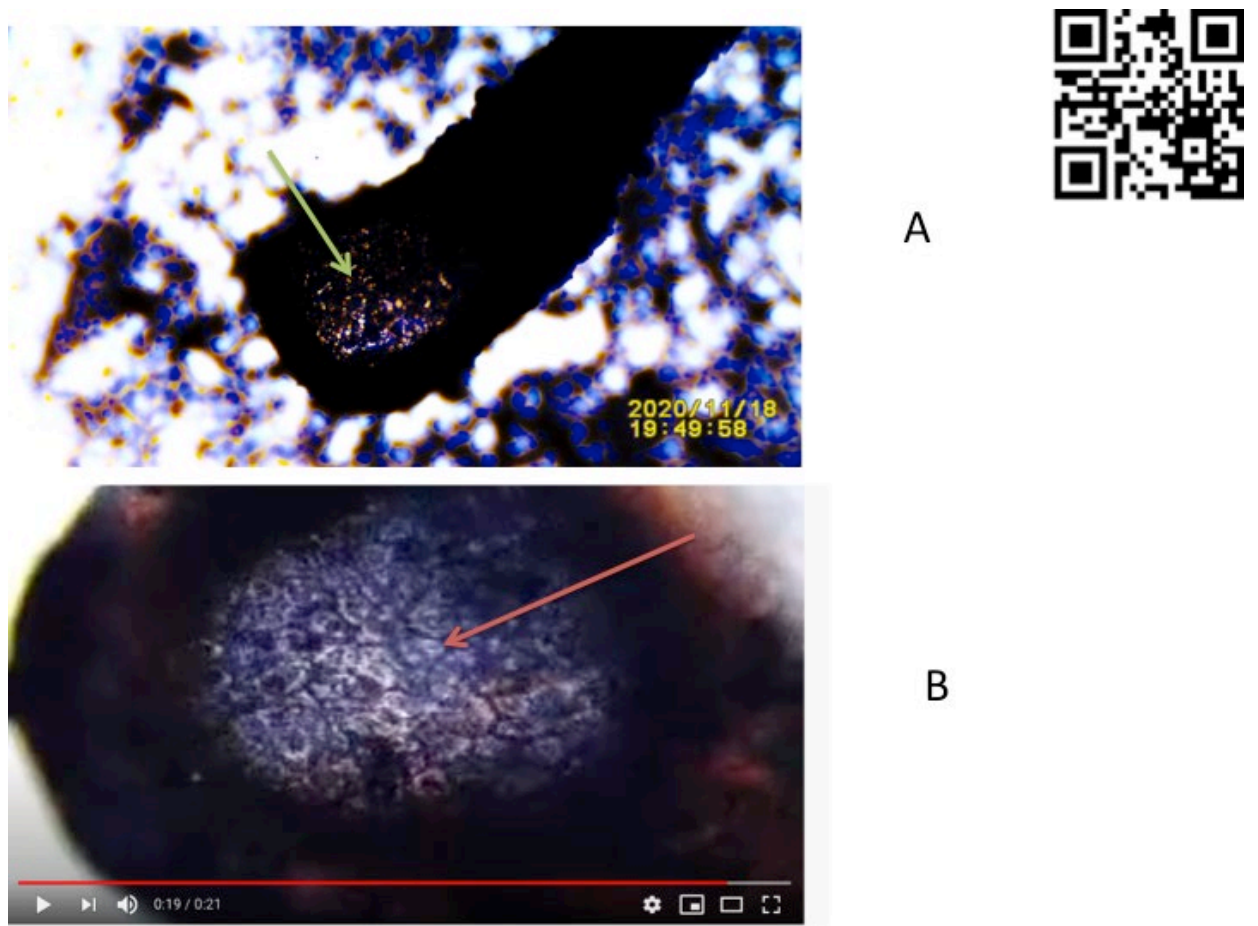

A

B

Figure 6: Panel showing: A: Hair follicle in liquid tetracycline after evaporation- Red Arrow: Pointing at the biological active Dermal Papilla (DP) area showing tetracycline crystals adherence. B: Amplified image from attached video frame at 0:19". Test showing crystals adhesion to the DP. For additional details, please link to URL

https://youtu.be/XC1XZdqJeqI Or scan QR Code in upper right corner of image. 
The Human Hair Follicle as Sentinel for Drugs Evaluation: Demonstration of Tetracycline Adhesion to Hair Follicle as Proposed Mechanism in Dysfunctional Hair Loss

Amplified Figure 6 Showing Tetracycline Crystals Adhesion to Hair Follicle Outer Membrane and Dermal Papilla Area.

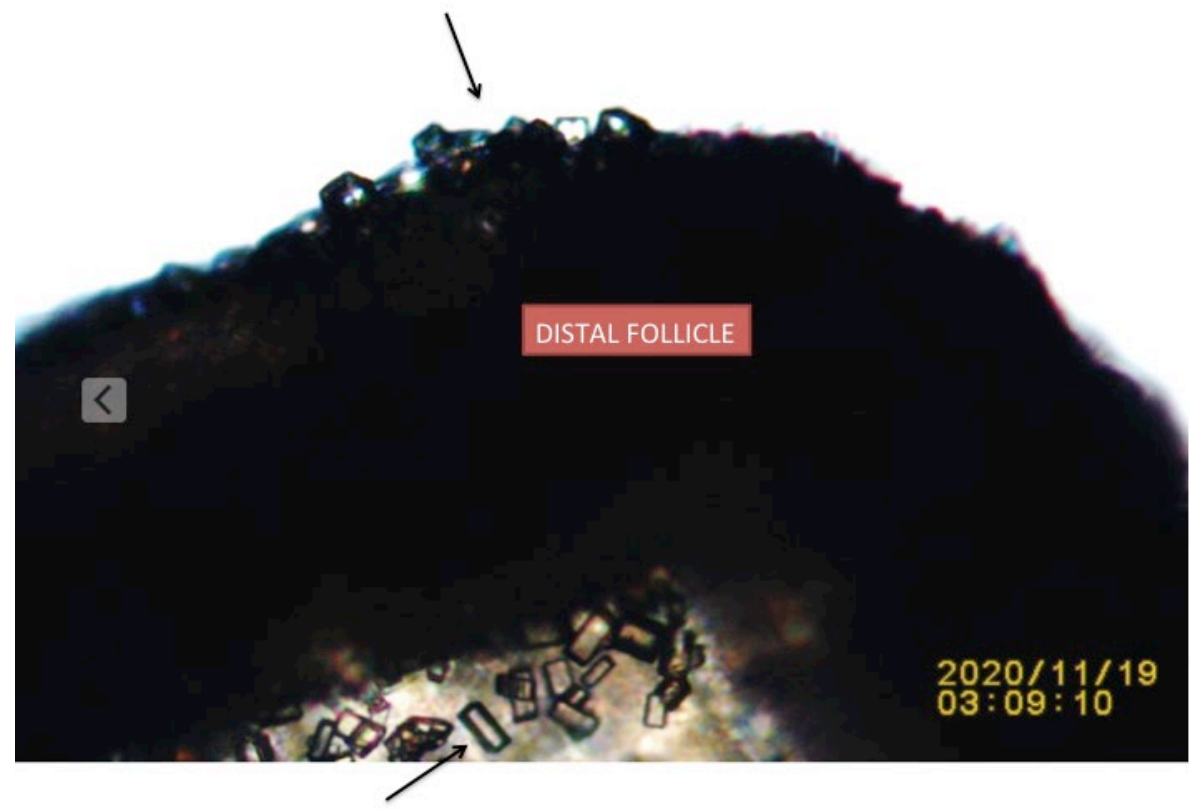

Figure 7: Microphotograph of amplified distal follicle displayed in Figure 6 showing: Black Arrow: Tetracycline crystals adhering to outer membrane and dermal papilla area.

\section{Time Dependent Cellular Changes in the Biological Active Dermal Papilla}

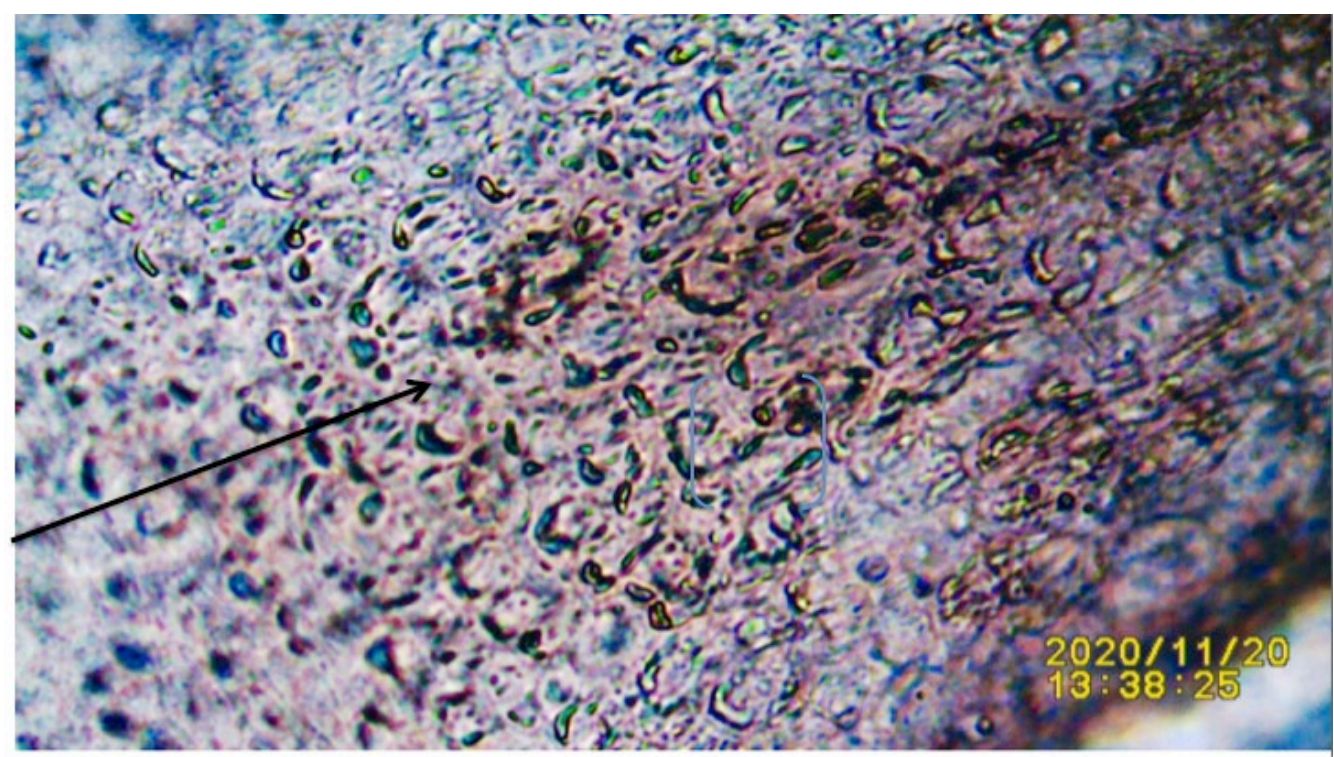

Figure 8: Time 13:38:25 Control hair follicle showing: Black Arrow: Dermal Papilla cells. 


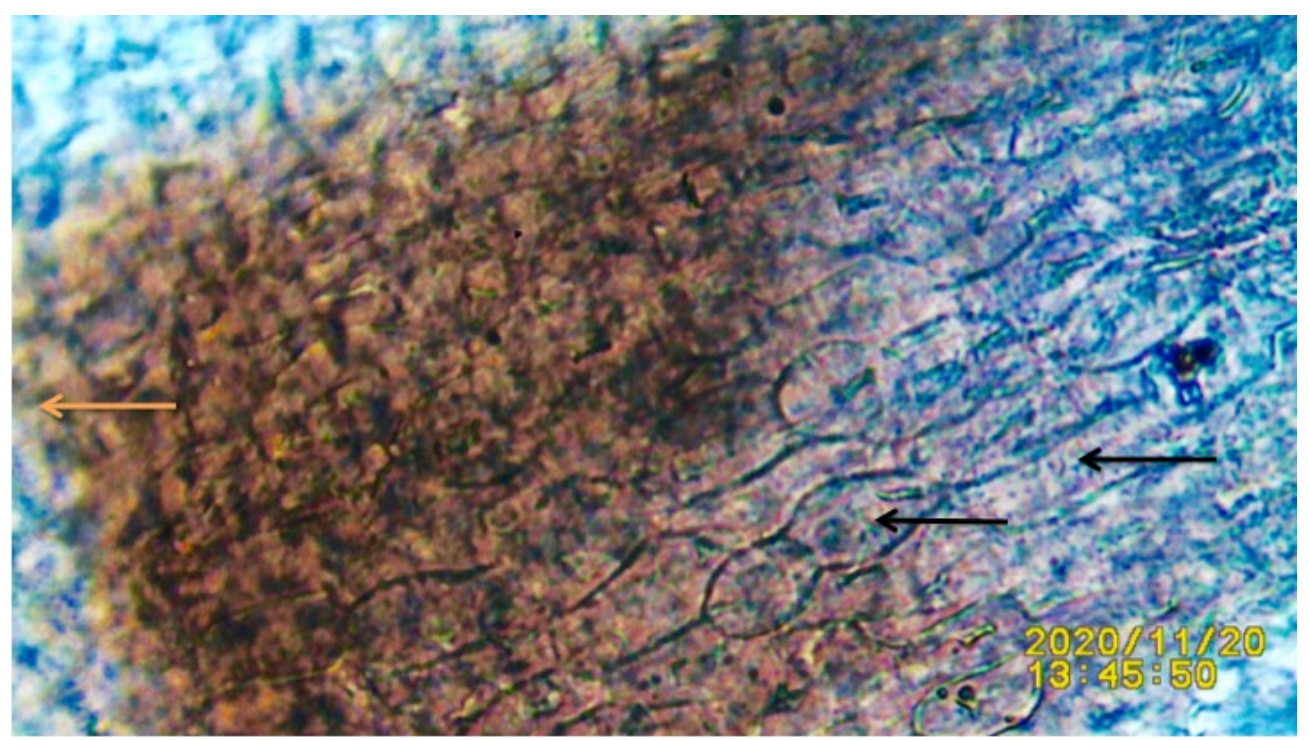

Figure 9: Time 13:45:50 (7 mins 25 seconds later). Same Hair follicle. Same area as control image above. Time: 13:45:50 now post sprinkling tetracycline crystals on hair, Black Arrows: Showing deformed cells. Orange Arrow: To skin.

\section{Disruption of Potassium Ferricyanide Crystals Deposition Caused by Tetracycline Induced Effect on Hair Electromagnetic Emissions}

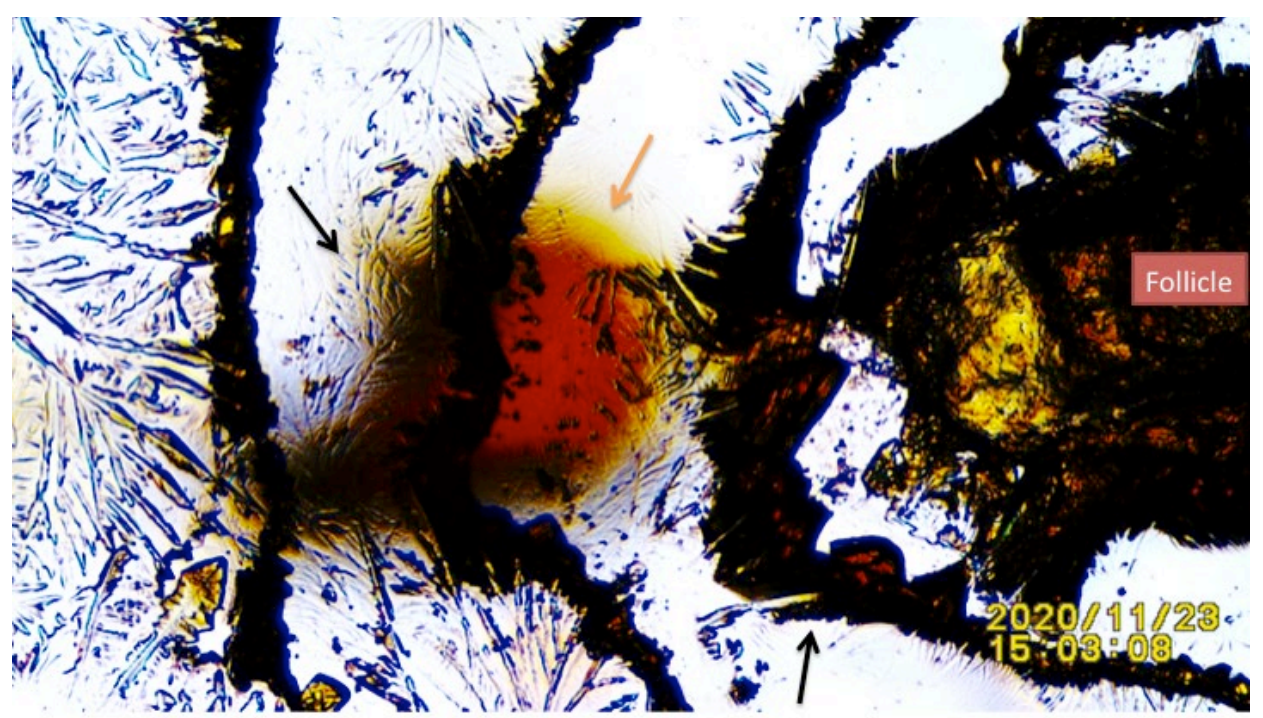

Figure 10: Hair in SSP K3Fe with dry liquid tetracycline SDW. Black arrows pointing at disturbed Potassium Ferricyanide crystals due to energy interference from Tetracycline penetrating a $1 \mathrm{~mm}$ glass barrier. Red Arrow:

Out of focus dry tetracycline. Black Arrow: Disturbed full absorption of electromagnetic waves by Potassium Ferricyanide.

The reader is encouraged to link to reference [9] figure 2A, where clarification of the hair follicle electromagnetic emissions is delineated:

https://doi.org/10.29121/granthaalayah.v8.i10.2020.1568

\section{DISCUSSION}

In this manuscript, in vitro experiments, the effect of the synthetic antibiotic Tetracycline (Doxycycline) was evaluated by using human hair follicles as sentinels. The experiments show:

1) A strong affinity of the antibiotic towards keratin. 
Figures 3,4,5.

2) A strong time dependent cellular changes and adhesive preference to the metabolic engine of the follicle a.k.a Dermal Papilla (DP). As note of interest, the antibiotic has been shown to inhibit prevalent cell-free protein synthesis $(7,8)$.

Figures 6,7,8,9

3) The antibiotic fluorescence under UV light was detected in all compartments of the human hair. Figure 1A

4) The adhesive property of the antibiotic allowed for time dependent documentation of cellular changes in the dermal papilla, as well as a disruption of the energy emissions (metabolism) of the hair follicle. Figure 10.

\section{SUMMARY}

Tetracycline causes structural physical damage as well disruption in metabolism demonstrated by changes in the orderly electromagnetic radiation emissions of the human hair follicle.

A demonstration of the usefulness of the human hair as sentinel for drugs evaluation is reintroduced. The first paper showing the deleterious effect of increased blood alcohol levels disrupting the follicle's energy emissions (9). This time the effect of a commonly used antibiotic (tetracycline) is shown as to cause structural damage and disruption on the intrinsic follicle's energy emissions. This finding is supported by another report where experimentally depleted Mitochondrial DNA (mtDNA) mouse resulted in increased number of dysfunctional hair follicles; and after a diet of Doxycycline which is a synthetic Tetracycline, fifty percent animals in the study died around 40 days and the remaining within 150 days. Conversely, in the same report, a month later after doxycycline induction was stopped, restoration of depleted mtDNA occurred. The authors of the study concluded, "In the present study, we demonstrate that mtDNA depletion-induced phenotypic changes can be reversed by restoration of mitochondrial function upon repletion of mtDNA", in other words, in mtDNA depleted mouse population, tetracycline infusion was documented to have a lethal effect; and this effect was reversed by a timely discontinuation of the infusion.

The experiments herein presented correlate and confirm previous findings of long-term exposure to tetracycline causing not only damage to pathogens; but also healthy human cells.

\section{ADDENDUM}

The photos and caption below support the reversal of a deleterious effect of Doxycycline (Tetracycline) induction on the hair follicles.

Based on the findings presented, it could be concluded that the adhesive property of the antibiotic is identified as a mechanism for its cellular effects.
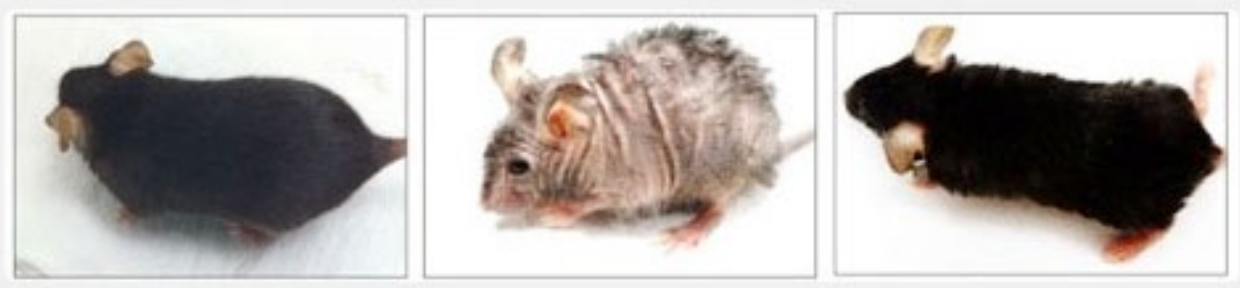

These photos show the hair loss and wrinkled skin after two months of doxycycline induction, and the same mouse a month later after doxycycline was stopped, allowing restoration of the depleted mitochondrial DNA.

Image and caption reproduced from reference listed below under Springer Nature reasonable sharing for noncommercial personal use 
Singh, B., Schoeb, T.R., Bajpai, P. et al. Reversing wrinkled skin and hair loss in mice by restoring mitochondrial function. Cell Death Dis 9, 735 (2018). https://doi.org/10.1038/s41419-018-0765-9

\section{SOURCES OF FUNDING}

This research received no specific grant from any funding agency in the public, commercial, or not-for-profit sectors.

\section{CONFLICT OF INTEREST}

The author have declared that no competing interests exist.

\section{ACKNOWLEDGMENT}

The author acknowledges the invaluable help of Benjamin Befeler MD (University of Miami Professor) for he historical perspective on Tetracycline and its Fluorescence property on cancerous gastric cells, as well as for the supply of $500 \mathrm{mg}$ Tetracycline capsules.

\section{REFERENCES}

[1] Embí Abrahám A. BS. (2020). THE DRUNKEN HAIR: INTRODUCING IN VIVO DEMONSTRATION OF INCREASED BLOOD ALCOHOL CONCENTRATION TEMPORARY DISRUPTING HUMAN HAIR FOLLICLES $\begin{array}{llllll}\text { EMISSION OF } & \text { ELECTROMAGNETIC } & \text { RADIATION. } & \text { IJRG } & 8(10), & 130 .\end{array}$ https://doi.org/10.29121/granthaalayah.v8.i10.2020.1568

[2] VASSAR PS, SAUNDERS AM, CULLING CF. Tetracycline fluorescence in malignant tumors and benign ulcers. Arch Pathol. 1960 Jun; 69:613-6. PMID: 13841453.

[3] Singh, B., Schoeb, T.R., Bajpai, P. et al. Reversing wrinkled skin and hair loss in mice by restoring mitochondrial function. Cell Death Dis 9, 735 (2018). https://doi.org/10.1038/s41419-018-0765-9

[4] Mosquera-Sulbaran, J.A., Hernández-Fonseca, H. Tetracycline and viruses: a possible treatment for COVID19?. Arch Virol (2020). https://doi.org/10.1007/s00705-020-04860-8

[5] Bin, B. H., Bhin, J., Takaishi, M., Toyoshima, K. E., Kawamata, S., Ito, K., Hara, T., Watanabe, T., Irié, T., Takagishi, T., Lee, S. H., Jung, H. S., Rho, S., Seo, J., Choi, D. H., Hwang, D., Koseki, H., Ohara, O., Sano, S., Tsuji, T., ... Fukada, T. (2017). Requirement of zinc transporter ZIP10 for epidermal development: Implication of the ZIP10-p63 axis in epithelial homeostasis. Proceedings of the National Academy of Sciences of the United States of America, 114(46), 12243-12248. https://doi.org/10.1073/pnas.1710726114

[6] Marlon R.Schneider, RuthSchmidt-Ullrich, RalfPaus (2009) The Hair Follicle as a Dynamic Miniorgan Volume 19, Issue 3, 10 , Pages R132-R142

[7] Day L. E. (1966). Tetracycline inhibition of cell-free protein synthesis. II. Effect of the binding of tetracycline to the components of the system. Journal of bacteriology, 92(1), 197-203. https://doi.org/10.1128/JB.92.1.197-203.1966

[8] Irwin M. Freederg (1970) Hair Root Cell-Free Protein Synthesis. Journal of Investigative Dermatology Volume 54, Issue 2, February 1970, Pages 108-120 https://doi.org/10.1111/1523-1747.ep12257131

[9] Embí Abrahám A. BS. (2020). THE DRUNKEN HAIR: INTRODUCING IN VIVO DEMONSTRATION OF INCREASED BLOOD ALCOHOL CONCENTRATION TEMPORARY DISRUPTING HUMAN HAIR FOLLICLES EMISSION OF ELECTROMAGNETIC RADIATION. International Journal of Research -GRANTHAALAYAH, 8(10), 123-130. https://doi.org/10.29121/granthaalayah.v8.i10.2020.1568 